\section{Delving inside the cell}

\section{L.G. Lajtha}

Cell Biochemistry and Function.

Editor E.M. Crook.

Butterworth. 4/yr. Subscription rates for 1985 not available.

THE admirable editorial in the first issue of Cell Biochemistry and Function (CBF) indicates such a wide scope that it is difficult to say what precise niche the journal is attempting to fill. The aim appears to be to cater for studies of a biochemical nature on intact, whole cells. Certainly, although it is not specifically stated, the editors are obviously aware of the current emphasis on compartmental studies and of the biochemical challenges to be found in intracellular micromilieux and microanatomical structures.

An especially useful feature is the commissioned reviews, particularly the multi-authored ones which tackle a particular subject (for instance the fivepaper review of mammalian alkaline phosphatase). Also included are short communications, full-length papers (with laudably detailed abstracts), conference reports, calendars of meetings, book reviews and, at the end of each volume, author and subject indexes.

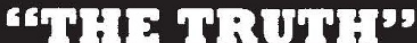 THE \\ ATOMIC COMPLEX}

\section{by BERTRAND GOLDSCHMIDT}

An accurate, complete and fascinating worldwide political history and personal memoir of nuclear energy - from the development of the bomb in World War II to today's nuclear energy complex and proliferation problems.

\section{NUCHARE TODEY}

Goldschmidt, a leading French scientist turned international statesman, reviews half a century of political moves, countermoves, international intrigue and manipulation. The Atomic Complex is a pragmatic look at the nuclear world today, carefully examining the terror nuclear weapons represent, but at the same time stressing the benefits of nuclear energy.

Order this 500 page

best seller today.

\$31 Hardbound \$24 Softbound

American Nuclear Society 555 North Kensington Avenue La Grange Park, II 60525 USA
The journal is nicely designed and produced - I particularly like the doublecolumn presentation - but while the paper is of good quality, it does not give as much contrast to electron micrographs as one would like. It is truly an international publication, the papers coming from respectable laboratories all over the world, and the standard of contributions is high, both in science and in writing; the declared rights of the editor to make such editorial amendments as are deemed necessary does result in a pleasant uniformity and clarity of style.

I think that $\mathrm{CBF}$ will appeal to a wide

\section{Thinking small}

\section{Richard W. Lacey}

Journal of Microbiological Methods.

Editor-in-chief D.C. White.

Elsevier Biomedical. 12/yr. Dfl. 510.

Diagnostic Microbiology and Infectious

Disease.

Editor-in-chief William J. Martin.

Elsevier Biomedical. 4/yr. \$132.

LIKE the cultures which so many of them discuss, journals on microbiological matters are proliferating. Do these two new contenders give readers (and authors) good value?

Each issue of the Journal of Microbiological Methods (JMM) contains about six substantial papers on aspects of the physiology, ecology and pathogenicity of bacteria (rather than of any other microorganism). While the science is sound, most of the methods reported are specialized in scope and will appeal largely to workers in each specific field; so while libraries should stock the journal, there will be few individual subscribers. The text is readable - presumably reflecting high editorial standards - and the presentation is good; indeed it is not unlike that of the Journal of General Microbiology, to which some of the papers might have found their way. On the debit side, the photographs could perhaps be improved, and I wonder whether enough experimental details are given for the non-expert worker trying to reproduce the experiments.

To date most papers have been published within a few months of acceptance, but quite a number suffered delays due to revision. Was this because authors were not familiar with the journal's style, or did the editors demand improvements in presentation or in scientific content? Whatever the case, prospective authors would certainly not jeopardize their reputation by publication here.

I can be less positive about the stablemate of JMM, Diagnostic Microbiology and Infectious Disease (DMID). Each issue contains about eight full-length papers with a variable number of shorter contributions. Most papers are published

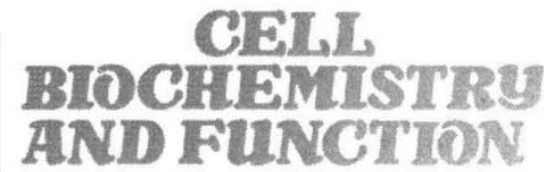

range of readers, although for four issues of about 65 pages each the subscription ( $£ 80$ in 1984 ) is on the expensive side. The journal is a sound vehicle for studies of modern intracellular biochemistry and I suspect it will not remain a quarterly for long.

L.G. Lajtha is Emeritus Professor of Experimental Oncology, University of Manchester. within six months of receipt, although here, too, many were revised. The standard of detailed editing seems to be high, and the presentation is again good.

The scientific content, however, is variable. The first issue of the journal (March 1983) contains a number of papers commenting on the antibacterial activity and sensitivity-testing of new antibiotics in arbitrary and uncritical ways. In them the objective in the synthesis of new antibiotics is apparently seen to be the identification of an agent with the broadest spectrum and lowest minimum inhibitory concentration. But surely the object of diagnostic microbiology should be rapid and accurate diagnosis, enabling the use of antibiotics wth minimum selection pressure?

Contributions in later issues of DMID do fortunately manifest such an approach. Some of them could have been published in the Journal of Infectious Disease, and are of almost comparable standard, but it is difficult to see reasons for some work being undertaken, let alone published. For example, a paper in the January 1984 issue deals with Pheumocystis carinii infection in germ-free rats, concluding that "These data have significant implications for the natural history, diagnosis and epidemiology of $P$. carinii with regard to

\section{DIAGNOSTIC \\ MICROBIOLOGY \\ ANDINFECTIOUS \\ DISEASE}

the human host"'. Such a comment is extremely disturbing, when it is appreciated how much the disease and therapy differ between the rodent and human being.

The journal seeks publications from clinical microbiologists and infectious disease specialists, but I remain unconvinced that members of either of these groups should deflect their energies in this direction, particularly at the expense of their clinical work. How many of our nosocomial infection problems are generated by neglect? Does our interest in novel antibiotics provide the need for these agents? $\square$

Richard W. Lacey is a Professor in the Department of Microbiology, University of Leeds. 